\title{
SERBIAN SECURITY PERCEPTIONS: MOTIVATIONS TO SERVE
}

\author{
Nebojsa NIKOLIC
}

\begin{abstract}
An empirical study was conducted to find out the level of propensity to serve in the Active Reserve of the Serbian armed forces and Ministry of Defence according to a newly established concept of manning. The concept of Active Reserve corresponds to similar concepts in other countries and is of growing importance and actuality, particularly in countries which have recently abandoned their military conscription system aiming to create professional military forces that citizens can join voluntarily. The concept of Active Reserve assumes that a citizen signs a contract with the Ministry of Defence, confirming his or her willingness and readiness to serve in the military on call, while in the meantime living and working on their own. Active Reserve offers mutual benefits: it relaxes temporary problems related to manning of military units and is a source of additional money for individuals engaged in it. One of the main questions related to the Active Reserve is the level of propensity to serve in it, while equally interesting is the investigation of motivational factors which stand behind the willingness to serve. The results show a very high propensity of population to serve in the country and a significant level of readiness to participate in peace missions abroad. The structure of motivational factors to join the Active Reserve indicated a meaningful level of a security awareness of the population. These findings are in concordance with some novel results about security perceptions in the South-Eastern Europe, including Serbia.
\end{abstract}

Keywords: Military organisation, manning, recruitment, Active Reserve, motivation, ranking, security, Serbia, South-Eastern Europe.

\section{Introduction}

The Active Reserve is a specific component of reserve military forces which are part of the overall military personnel. Missions, organisation, structures and other important aspects of the military organisation, including the Active Reserve, are defined by law and strategic documents at national level. These strategic documents dedicated to security issues might include: national security strategy, white paper on security and defence, strategic defence and security review, etc. In Europe, there are also common strategic documents at the level of the European Union. ${ }^{1}$ However, there is no broadly accepted methodology for shaping national security strategies, nor unification of structure, content or other aspects. One of the structural elements that 
is included in almost all of these top security documents is a statement about the main security challenges, while other structural elements, approaches and coherence issues differ significantly from country to country, making some strategic documents better, and other less fit for purpose. ${ }^{2}$ These theoretical findings sound reasonable if we have in mind major security challenges that Europe faced in the last few years (large-scale migration, floods, fires, volcano eruptions, armed conflicts, failing states, terrorism, unrest, gas pipelines violation, corruption, etc.) and corresponding response measures that have been undertaken at national, regional or European level. All these events and research findings justify current efforts at national and, particularly, at European level towards reengineering of the collective security system. Comprehensive, methodologically sound and impartial, multidisciplinary, interagency and multinational approach is certainly necessary, as well as feasible. ${ }^{3}$

Perception of security threats and challenges for Serbia, through the prism of the main public media and common people, is dynamic and influenced by the intensity of current events. For example, in the late spring of 2014, there were big floods with extensive impact on many people and industries (e.g. some facilities of the main electric power plants were seriously threatened and damaged) and the Serbian Army, among many other subjects and organisations, including an international component, provided substantial contribution for mitigating the consequences of the crisis. Periodically, almost every year around some holidays, the frequency and fatality of traffic accidents draw the attention of the public and consequently traffic challenges are escalated as a problem that has to be solved somehow by somebody. Unlike the mentioned challenges that sporadically affect the security discourse, there are some stable, persistent security concerns for the population, and some of them like economic challenges and corruption are particularly salient. Transitional economies have well known problems: low wages, uncertain employment status, very high unemployment rate, high taxes, complex bureaucracy, weak consumers' protection, etc. Corruption is something that is very hard to prove but its dimensions and outspreading are epic and many people feel it as one of the most important problems in the country ${ }^{4}$ (while this report mainly considers bribery, there are many other forms of corruptive behaviour).

Security threat analysis is one of the starting points for developing and adjustment of national security and defence strategies. Unlike the Cold War epoch when dominant security threats were clearly visible, stable and predictable, in modern times there is a broader set of security threats that are more uncertain and more dynamic. Political elites in modern governments are more prone to engage national defence forces and resources abroad in order to gain international recognitions and prestige or to fulfil international obligations of their countries (to UN, EU, NATO). On the other side, there is a general trend of decreasing defence budgets, downsizing military units and 
defence personnel, paralleled by suspension of conscription as one of the main sources of manning traditional armies. Additionally, almost all European states are characterised by the unique situation of some kind of a "peace dividend" which is a result of the membership in the European Union and/or NATO. This, together with other factors, contributes to the discussions about the role and purpose of modern defence forces in complex contemporary conditions. ${ }^{5}$

The concept of Active Reserve could be perceived as a response to the dual constellation of contemporary security threats and, on the other hand, to the trend of downsizing military forces and defence budgets. One well known phrase- - Doing more with less" - describes adequately the situation of the modern military in the modern society in many countries. In the organisational sense, the Active Reserve component is a supplementary entity to the existing military units and defence organisations. In the case of the Serbian Army, the members of the Active Reserve will fill vacant positions in regular (existing) military units and Ministry of Defence's organisations, rather than forming some separate organisational entity composed of active reservists only.

The armed forces are still the "last resort" of the state and society, particularly in large-scale natural or man-made disasters. This became evident during the heavy floods in Serbia in May 2014, but also in Bosnia and Herzegovina, as well as in Croatia. After these events, later that year, those countries increased their efforts towards implementing the concept of the Active Reserve.

\section{Basics of the Active Reserve Concept}

Under the term Active Reserve (AR), in this paper, we assume the case when a citizen concludes a contract with the Ministry of Defence (MoD) to respond to the call of duty when he or she is called upon by the military organisation. In return, the member of the AR will be paid for his/her predefined readiness to be engaged and for the engagement itself. While engagement in AR is occasional, in the meantime the AR member works and lives a normal civilian life. The term "Active Reserve" is used in this context in Serbia, ${ }^{6}$ but also in the Netherlands, Lithuania, and the Czech Republic. Besides this term, there are few more terms in use, essentially marking the same concept, and those include: Selected reserve (USA, Italy); Reaction forces (Denmark); High Readiness Reserves (UK); Alert Reserve (Poland); Operational Reserve (Romania); Immediate Available Reserve (Belgium).

The suspension of conscription has been one of the main trends in military transformations across Europe, and particularly in Eastern and Southeast Europe in the last 25 years, resulting in the fact that the majority of European states now have all-volunteer forces. ${ }^{7}$ A direct effect of the conscription's suspension is a change in the way military organisations obtain soldiers. Recruitment for all-volunteer forces is based 
on a voluntary decision of interested citizens. This moment (voluntarism), involves an important level of uncertainty in planning and military personnel policy, as well as the emergence of needs to indicate the level of propensity and spectra of motivation $^{8,9}$ of the population to enter military service, in this case - in the Active Reserve.

The conscription system of manning the Serbian armed forces was suspended in December 2010 by a decision of the national parliament. Instead of conscripts, professional military soldiers serving under time-limited contracts became the dominant category of soldier. Voluntary military service has been organised around few training centres for basic military training. The duration of the basic military training is two and a half months and, after that, there are additional few months of specialised training for different military occupational specialties. Currently, there are four training centres for basic military training. Each centre in each training tour has about 150 to 200 of young volunteers attending it. In the last few years, there have always been more interested candidates than available places for volunteer military service. The number of potential candidates for professional soldiers will be drastically reduced after 2020 because of age limits. Namely, at that time the last generation of conscripts will enter the age that is the limit for embarking on a professional military career.

The conceptual importance of AR and its purpose will likely grow in the future, while some European countries are facing this problem today. ${ }^{10}$ Furthermore, other issues and questions related to the reserve component of the armed forces will be gaining an increasing importance (recruitment, selection, sustaining expertise, security clearance, right force mix between Active and Reserve personnel, etc.), even in developed Western countries with long-standing experience. ${ }^{11}$ In the time of declining military budgets and growing responsibilities, military organisations realise that part-time soldiers could span periodical needs for military human resources engagement.

The main goal of the AR concept is to sustain a required level of operational and functional capabilities of military units, staffs and organisations in ministries of defence. To achieve that, AR members are expected to be invited for the training exercises and check-ups more frequently than the other people in the common reserve pool. Military reserve in general has a very important role in the defence matters in wartime, as well as in a peacetime, when large-scale emergency situations demand it, such as floods, earthquakes, fires, etc. The force mix, specifically the ratio between active and reserve forces, is a subject of consideration and decision-making at strategic level. In different countries the issue is tackled differently: from absolute dominance of the active component to substantial contribution of the reserve component. 
For example, the system of reserve forces is one of the cornerstones in the Israeli Defence Forces (IDF), providing about two thirds of overall defence manpower. ${ }^{12}$

Military reserve has a potential to be the best pool for efficient personnel recruitment in a long-term vision. There are several reasons for this statement: filling vacancies in military units, using competencies of reservists, economy of human and financial resources and developing and sustaining links between the military organisation and civil society. ${ }^{13}$

After finishing voluntary military service (consisting of a two-phased military training) in Serbia, volunteers are free to decide whether they will go back to their civilian life or they will apply to become professional soldiers. Having finished basic military training is one of mandatory preconditions for getting employment as a professional soldier under contract. The described process serves as the main tool for obtaining candidates for professional soldiers, as well as for pooling potential candidates for the reserve component of the armed forces. Non-commissioned officers are recruited from the population of professional soldiers, while officers are obtained mainly from the Military Academy (an alternative way is to finish reserve officers school after previously having finished some civilian university). However, the military organisation has recognised the need for some additional mechanisms for manning its units and the MoD's organisations. AR is one of those solutions in the Serbian case.

The top management of the military organisation expressed an interest in considering the population's level of propensity to serve in AR before making concrete decisions. Additionally, besides propensity, other questions of interest might include: motivational factors standing behind willingness to serve, expectations, age, gender, education structures, and others. This paper presents the results generated from an empirical research about propensity and motives of citizens of Republic of Serbia to engage themselves in a specific kind of military service marked here as "Active Reserve." The next section describes the conditions and general notes about the conducted research. This is followed by the results of the empirical research that contains motives and levels of propensity to serve, as well as some additional findings.

\section{Notes on Research about Propensity to Serve in AR}

The Strategic Research Institute of the Serbian MoD conducted an empirical research about propensity of citizens to be voluntarily engaged for military service through the mechanism of AR. The research has been performed during the last quarter of 2014. An electronic questionnaire ${ }^{14}$ was posted on the Internet site of MoD and was supported by a short but intensive marketing campaign in media (TV, main newspapers) about the concept of AR in general. Every visitor has been free to access and fill it in. In the period November-December 2014, a total of 708 useable filled-in questionnaires were received. Involving modern technologies (electronic questionnaire, Inter- 
net, automated gathering of sample data) in an empirical research of this type in the defence branch was relatively (if not absolutely) new compared to current practice in the country. Technology enablers are thus of great help, particularly in cases of scarce research resources or when meeting tight deadlines is considered critical.

The empirical research was based on the questionnaire, consisting of two main parts. The first part consists of 14 questions, with 10 of them related to general data like age, gender, education level, profession/vocation; two questions on the level of awareness and the sources of information about the AR concept; and two questions about the participant's expectations for financial gain from the AR engagement. The second part of the questionnaire consists of 21 questions related to the level of propensity to serve in the AR and motivating factors to enter the AR. The design of this questionnaire has been positively influenced by other studies ${ }^{15}$ on similar topics.

General findings from the empirical research are as follows. The sample has achieved 708 electronic responses in a period of less than a month, and the general characteristics are:

- Employment status of respondents: $60 \%$ unemployed, $40 \%$ employed.

- Previous military experience (completed military service): $42 \%$ not finished military service; and $58 \%$ finished regular military service with weapons.

- Geographical distribution of participants: $34 \%$ from Belgrade (the capital of Serbia represents roughly about one quarter of the whole population), $21 \%$ from Vojvodina region in the north, and $45 \%$ from the rest of the country.

- Educational background of respondents: $8 \%$ have finished elementary school; $55 \%$ have completed high school; $10 \%$ have received bachelor's degree; and $27 \%$ have obtained a master's degree.

- Marital status: $63 \%$ not married; $37 \%$ married.

- Age structure of the participants was the following: $35 \%$ were up to 25 years and $65 \%$ were from 26 to 32 years of age, which confirms a wellknown fact that younger people are more familiar with modern technologies than older generations. However, there is another possible reason for the absence of respondents above the age of 32 , namely the age limit for service in the AR (40 years) and for professional soldiers (30 years).

- Gender structure: $12 \%$ of the respondents were female and $88 \%$ - male.

The representativeness of the sample obtained in this empirical research could be considered good enough for the declared goal of indicating the level of propensity to serve in the AR. There are a number of considerations in favour of this. The sample size is large enough, given the MoD's vision for the number of the initial contingent of active reservists (MoD announced a public call ${ }^{16}$ for one hundred volunteers for 
the Active Reserve on 1 March 2015); also, the sample size in this research is of the same order of magnitude as the samples in other studies ${ }^{17,18}$ on similar topics. However, it is a small sample considering that population in Serbia exceeds seven millions inhabitants. In account of the good geographical distribution of participants across main regions, a sample size of 708 participants is not sufficient to make estimations at a single municipality level (there are more than 170 municipalities in Serbia). Educational and employment aspects in the sample show a good balance (in the sense that it is not surprising), as well as the age factor and the marriage status. On the other hand, in this kind of empirical research it is always good to be cautious because of the following: information awareness of the population about the possibility to serve in the AR is not absolute, that is, in spite of the broad impact of Internet and other media (TV, radio, newspapers) in modern life, it is still possible to find a large number of uninformed individuals regardless of the reason, e.g. lack of access to the Internet or missing some information in other media.

\section{Propensity and Motives to Serve in the Active Reserve}

Focused questions about propensity and motives to serve in the AR logically belong to a broader field of investigating the population's perceptions of security. That is certainly an important issue, particularly for political and social scientists as well as for political activists. In Serbia, there are many organisations, particularly non-governmental ones, which deal with various issues in the security field. Besides the hard heritage of history (both recent and not so recent history) and its reflection in the high salience of traditional security concerns (e.g. territorial integrity, social stability), it could be said that the majority of people in Serbia are most concerned about economic prosperity, corruption and physical safety.

Different perceptions of security issues at different levels (states, organisations, individuals) are one of the fundamental problems even at the European Union level ${ }^{19}$ and it deserves more attention from the researchers. And on the contrary, when we get a match of the results from different subjects, then we can consider those results as very reliable and representative. So, the research findings that follow are not immune to different interpretations.

Two main questions of the empirical research were related to identifying the level of propensity to serve in the AR and indicating the level of willingness to participate in peace missions abroad (PMA) as a member of the AR. Participants were asked to answer the question by choosing one of five offered marks: from 1 ("absolutely disagree" to join to the AR and to participate in PMA) to 5 ("absolutely agree" to join the AR and to participate in PMA). As indicated in Table 1, empirical results showed very high propensity to join the $\mathrm{AR}$ (4.52) and high willingness to participate in PMA (3.99). 
Table 1: Propensity to join to the Active Reserve.

\section{PROPENSITY TO JOIN THE ACTIVE RESERVE}

(percentage representation of different answers; sample size 708)

\begin{tabular}{|c|c|c|c|c|c|c|c|c|c|c|}
\hline \multirow{3}{*}{$\begin{array}{c}\text { MAIN } \\
\text { QUESTIONS }\end{array}$} & \multicolumn{6}{|c|}{$\begin{array}{c}\text { RESPONDS } \\
\text { MARKS }\end{array}$} & \multicolumn{4}{|c|}{ STATISTICS } \\
\hline & 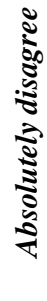 & 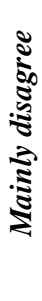 & 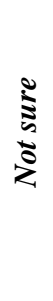 & 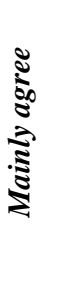 & 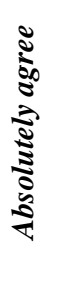 & 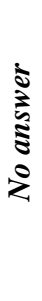 & 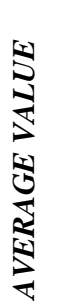 & 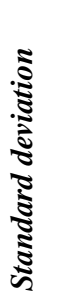 & $\underset{2}{2}$ & 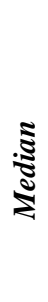 \\
\hline & 1 & 2 & 3 & 4 & 5 & l & & & & \\
\hline $\begin{array}{l}\text { "I am very interested to } \\
\text { join the Active Reserve" }\end{array}$ & 4 & 1 & 4 & 12 & 77 & 2 & 4,52 & 1,16 & 5 & 5 \\
\hline $\begin{array}{l}\text { "I am very interested to } \\
\text { participate in Peace } \\
\text { Missions abroad" }\end{array}$ & 11 & 4 & 9 & 17 & 57 & 2 & 3,99 & 1,46 & 5 & 5 \\
\hline
\end{tabular}

Participants in the research demonstrated a very high level of propensity to serve and that matched up well with the high level of general security awareness of the population detected in other research studies, particularly newer ones. ${ }^{20}$ Very high propensity level (Table 1), considered in constellation with motivation structure (Table 2), can mean that participants perceive the AR as an efficient way (temporarily engagement, limited obligations) to contribute to solving the security issues in the country (belonging to the defence forces). The concept of the AR seems a promising option for successful sustainment of a relationship between the military organisation and the society: almost every citizen can try to actualise his core values related to security and to give personal contribution to the response to the security challenges, by joining the AR.

There were 14 different motivational factors offered for evaluation as reasons for joining the Active Reserve. Participants were asked to assess each motive on the scale form 1 (,,absolutely disagree") to 5 ("absolutely agree“) according to their preferences. 
Responses were calculated and ranked as presented in Table 2. Motives in Table 2 are ordered by rank (from top importance at first place, to minimal importance at $14^{\text {th }}$ place), while the listing of motives is different in the questionnaire.

Data presented in Table 2 shows several things:

- The most dominant $(4,46)$ motive is "Patriotism," which is, in the original questionnaire, declared as "Love towards the country." This is a praiseworthy output, maybe expected in this kind of research (but it is always good to have it).

- Second $(4,21)$ dominant motive is "Acquiring new knowledge" and close to it in the fourth place $(3,85)$ is a similar factor: "Acquiring new qualifications." Both express expectations of participants about possible benefits they expect from an engagement in the Active Reserve.

- In the third place $(3,91)$ is a motive declared as "Fan of soldier's way of life." This result is worth a deeper study. It could mean preference towards higher standards of order and discipline, but also it could be a "romantic" opinion without experience from real military life and poor military comfort.

- Next in the line, in the fifth place $(3,37)$, is a motive defined as "Meeting new people."

- Surprisingly, "Money" as a motive is poorly ranked, occupying the twelfth place $(2,59)$ out of fourteen. It could be taken as a surprise because of the hard economic situation in the country.

- Before last ranked the motive "Health insurance" $(2,14)$. This result confirms the good level of participants' awareness and contributes to vanishing of some myths about different issues with prefix "military" (military hospitals have often been considered prestigious in the past). Participants simply do not see this as a reason to join the AR.

- The lowest $(1,7)$ ranked motive is "Opportunity to give orders," taken as an indicator of the maturity of participants.

Additional statistics in Table 1 and Table 2 confirm a modest dissipation around average values. Generated results about ranking order of motives (Table 2) could be commented differently. The author's perspective is one of the possible views which are trying to explain the meaning of the results. The low ranking (12/14) of the "Money" factor is a great surprise, however it could be seen as a consequence of the good awareness of participants (the following constellation is relatively well known among Serbian citizens: average salary of the professional soldier versus average salary in the state). Well ranked are factors with indirect economic effect: "Acquiring 
Table 2: Ranking motives for service in active reserve, statistics and ranks.

MOTIVES FOR JOINING THE ACTIVE RESERVE

(percentage representation of different answers; sample size 708)

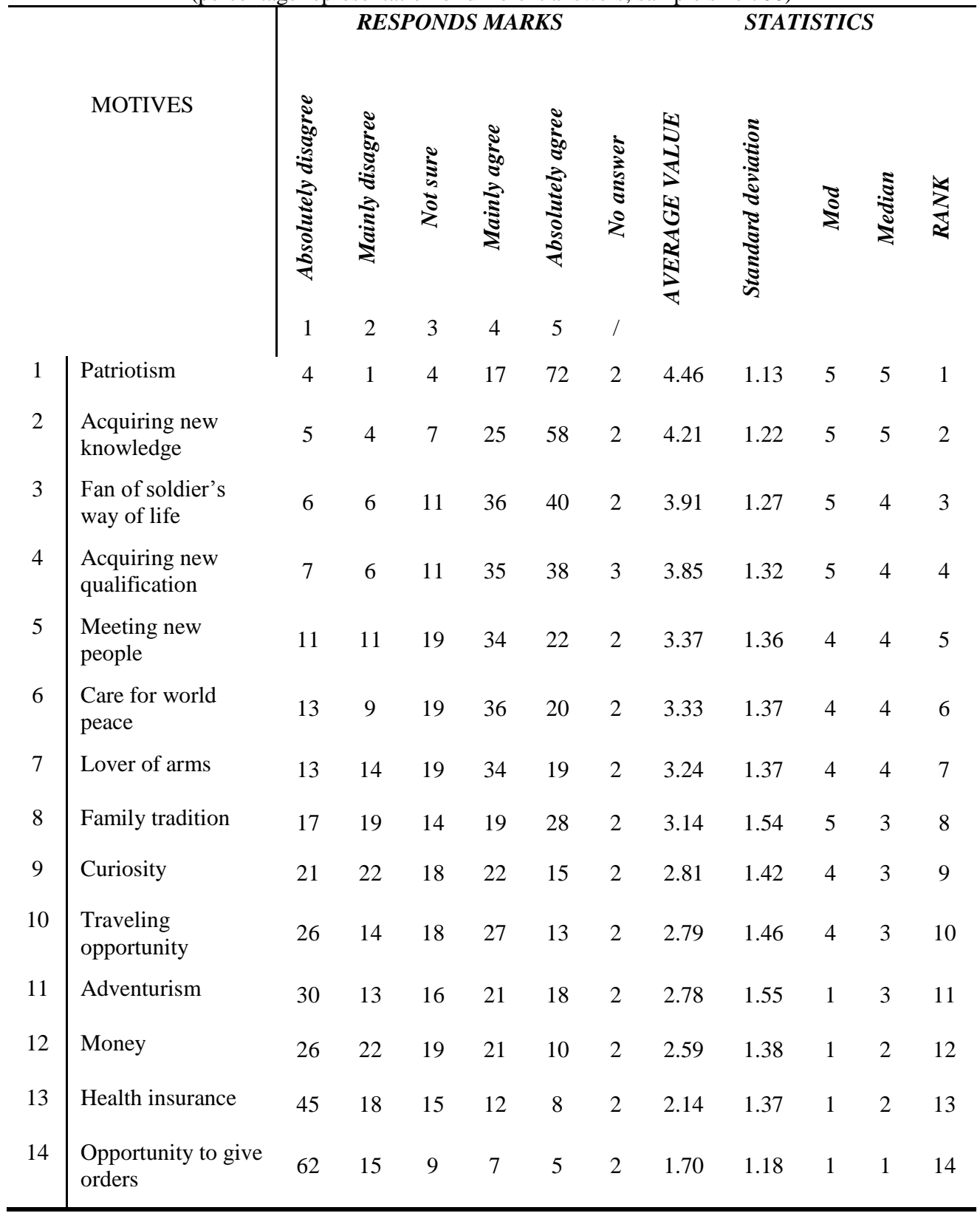


new knowledge" (2/14) and "Acquiring new qualifications" (4/14), which confirms the economic maturity and realistic approach of participants, indicating their expectations of financial benefits. The positions of these two motives coincide very well with appropriate results in two other research studies: a novel research involving a factor named "Economic Prosperity and Security" ${ }^{21}$ for the region of the South-Eastern Europe; and an older study for a wider circle of European states. ${ }^{22}$ Also, this result could be recognised as a very positive perception of participants about the military organisation as a reputable employer and a good place where they can find upgrades for their skills, knowledge and certifications.

The best ranking motive "Patriotism" can be understood in several ways: as an inner feeling and disposition of a person who wants to join a very specific profession. This is followed by no illusion about money gains, but, at the same time with very high expectations related to acquiring new knowledge and qualifications. The next view benefits from real data presented in other relevant research studies conducted for the region of the South-Eastern Europe, ${ }^{23}$ where it is indicated that the factor marked as "Territorial Integrity and Security" has medium importance. An even larger discrepancy is found in the ranking of this motive as compared to results in some earlier research, ${ }^{24}$ related to a broader set of European countries, where "Patriotism" was outreached by the following motives: Monetary benefits, Mission abroad adventure, Economic reasons, Educational benefits, and Tradition. However, with respect to the empirical results, a positive relationship could be established between challenges to territorial and physical security on one hand, and patriotic motivation to serve (in this case in the AR), on the other.

The comparison between these results and results from similar studies shows some differences, which is expected because security in each country or region is regarded differently, ${ }^{25}$ and also because of the different perspectives of the subjects ${ }^{26}$ that participate, formulate or estimate the security issue. However, there is one more dimension $^{27}$ in the security estimation, and that is time as a specific factor which means a security issue (in this case it is the ranking order of motives to join some form of military service) can change over time even in the case of the same country.

\section{Additional Findings}

One of the questions was oriented towards the identification of the dominant sources of information about the AR. This question has multilayered importance: it indicates practical ways of communication between society and the military organisation; it shows directions for effective communication in the future; and may help the Public Relations Department of the MoD to make corrections in resourcing different communication channels in order to sustain effective and efficient relations with society. 
Table 3: Sources of information about the military service.

\begin{tabular}{l|lc}
\hline & Source of Information about the Active Reserve & Percentage \\
\hline 1 & Newspapers, Radio, TV & 23,2 \\
2 & "Odbrana" Magazine & 3,7 \\
3 & MoD local territorial representatives & 3,8 \\
4 & Internet site of the MoD & 50,4 \\
5 & Friends & 9,6 \\
6 & Other sources or not declared & 9,3 \\
\hline
\end{tabular}

The best result among the sources offered scored the Internet site of the MoD, where 50 percent of the participants obtained information. The "Odbrana" magazine ("Defence" in English) was ranked last. It is a journal of the MoD and the Armed Forces of Serbia, issued bi-monthly under the supervision of the Public Relations Department of MoD. It is mainly oriented towards informing members and employees of the MoD and the Armed Forces of Serbia, but it is also available on the free market. Tellingly, respondents are rather informed by "Friends" than by the official magazine of the defence and local territorial representatives of the MoD. All other (civilian) newspapers, radio and TV stations were the source of information for 23 percent of the respondents. These results are not a surprise and confirm the fact that we are living in the age of Internet. Roughly $9 \%$ out of 708 participants in the survey opted for other sources or did not answer the question.

The next interesting finding is related to the answer about the vocation or profession of the contributor. The main idea behind this question was to gain an insight into the structure and diversity of vocations/professions of the respondents to the AR questionnaire. Good and appropriate vocational diversity allows better possibilities for satisfying the recruitment needs of the various military units, oriented towards engaging AR members. For example, if a military unit declares a need for a vehicle mechanic or a computer specialist, then it is evidently better to have a pool of interested civilians with the same or similar professional skills, knowledge and practice. It is better because it generates less demand for training, preparation time and resources.

Smart reserve recruitment assumes picking a civilian candidate for the AR with appropriate skills, education or even specified Military Occupational Specialty (MOS). In the past, in a period when the conscript system existed and military service was 
mandatory, every soldier completed basic military training but also some specialist military training, earning appropriate MOS code. However, today and particularly in a future period, the pool of reservists is becoming smaller. An efficient approach to solving this problem could be the redirection towards appropriate selection and the use of existing civilian skills of the reserve pool. The main idea relates to an expectation that the requirements for additional military training would be very relaxed, when the content of the training course is not completely new to the attendants. For example, a "wheel vehicle repairer" (one of the Military Occupational Specialties) should be recruited from the members of the reservist pool who perform similar tasks in their civilian life, i.e. among members that are car mechanics. More problems arise for those MOS which do not have an equivalent civilian occupation. In that case it is good to at least hit the general branch. For example, for MOS such as "artillery repairer," it is better to choose and train a reservist with skills in mechanics or metalworking than a reservist with skills in economics, cooking or something else far from the mechanical branch.

Respondents were free to define their vocation/profession as they like: that approach to the design of the questionnaire was user-friendly towards respondents. However, it generates the need for additional efforts in later analysis. In this approach we supposed that respondents will not be ready to make the effort and spend time in finding their official professional mark in a long list of professions. That was fruitful and we got a few dozens of different vocations after appropriate grouping.

The next interesting finding is related to gender issues. Gender composition of the sample includes slightly above $12 \%$ female respondents. At first sight, this seemed highly disproportionate, but it could well be seen as a big success from a gender perspective. Firstly, the concept of a wider participation of women in the military is relatively new to Serbia, so this result could be regarded as a success for the whole society. Secondly, the empirical research was anonymous, so this gender ratio comes as a result of the free will of contributors to share this information. Additionally, this proportion could be seen as a sign of the willingness of female population to enter military service. As a matter of fact, these $12 \%$ of female respondents in the Serbian research ( 88 female participants in a sample of 708) is a big success as compared to a similar research in Sweden, ${ }^{28}$ where there were only 11 female participants in a sample size of 666 (that is, less than 2\%)! This finding represents a collateral benefit of our research and it is really worth pointing out, taking into account that Sweden and the Swedish armed forces are among the few in the world considered as "benchmark states" when gender issues in the defence sector are considered. 


\section{Conclusions}

The concept of Active Reserve assumes a high level of readiness to respond to the call of the military organisation anytime during the contractual period. It is a result of a trade-off between needs (operational readiness) and possibilities (costs). Capacities obtained on the basis of the Active Reserve concept are less expensive than maintaining a whole unit in permanent operational status. On the other hand, the military organisation offers some money to those who are ready and willing to share their competencies, skills, time, and life-and-work schedule with the military organisation.

The findings from the empirical research show a very high level of propensity to join the Active Reserve, with the main motives being patriotism, acquiring new knowledge, attraction to military life, acquiring new qualifications and meeting new people. Collateral findings show substantial interest expressed by the female part of the population, as well as confirm the influence of modern technologies and Internet infrastructure on many aspects of everyday life. Empirical data was collected through an electronic survey and participants belong mainly to the younger population.

In the wider context of security issues, a high level of propensity for military service combined with expressed motivational spectrum, means that population has respectable level of security awareness. More specifically, the ranking order of motivational factors confirms the dynamic nature of security perceptions. Besides traditional factors (patriotism), elements of economic prosperity and security (qualifications and knowledge) have been placed near the top.

Future work is possible on further analysis of gathered empirical data and comparison with foreign experience on similar problems. Also, some longitudinal research could be of use in the future.

\section{Acknowledgement}

This work was partially supported by the Ministry of Education and Science of the Republic of Serbia under interdisciplinary Project No.III-47029 ("Cost Effective Selection of New Technologies and Concepts of Defence through Social Reforms and Strategic Orientations of Serbia in 21st Century").

\section{Notes}

1 See, for example, European Council, A Secure Europe in a Better World, European Security Strategy, 12 December 2003, available at www.consilium.europa.eu/uedocs/cmsupload/ 78367.pdf.

2 Olivier de France, Nick Witney, "Europe's Strategic Cacophony," ECFR/77 Policy Brief, European Council of Foreign Relations, April 2013, available at http://www.ecfr.eu/page//ECFR77_SECURITY_BRIEF_AW.pdf. 
3 Tim Swejis, Joshua Polchar, Boaz Manger, Willem Oosterveld and Laurin Nabuko Hainy, "Assessing Evolving Concepts of Security," Deliverable 3.1, EvoCS Consortium, 20 February 2015, available at http://dx.doi.org/10.11610/evocs.d31.

4 UNDOC, Statistical Office of the Republic of Serbia, "Corruption in Serbia: Bribery as experienced by the population," 2011, available at https://www.unodc.org/documents/dataand-analysis/statistics/corruption/Serbia_corruption_report_web.pdf.

5 John Clarke, "Europe's Armed Forces in Civil Security," Connections: The Quarterly Journal 12, no. 2 (2013): 69-82, available at http://dx.doi.org/10.11610/Connections.12.2.04.

6 Nikola Karanovic, “Active and Pasive Reserve," Magazine Odbrana 71, Special appendix, in Serbian (Belgrade, 2011).

7 Tibor Szvircsev, "Europe's Armed Forces in Transition: From Conscription to all-volunteer forces 1975-2014," International Workshop "10 Years after Suspending Conscription: Transition and Transformation," 3-4 December 2014.

8 Bryan Wiggins, Sarah Evans, Joseph Luchman and Jennifer Gibson, "Motivators and Barriers to Recruiting Prior Service Members in the IRR," Military Psychology 26, no. 1 (2014), available at http://dx.doi.org/10.1037/mil0000026.

9 Jami Taylor, Richard Clerkin, Katherine Ngaruiya, and Anne-Lise Knox Velez, "An Exploratory Study of Public Service Motivation and the Institutional-Occupational Model of the Military," Armed Forces \& Society 41, no. 1 (2015): 142-62, available at http://dx.doi.org.10.1177/0095327X13489119.

${ }^{10}$ Jiri Sedivy, "NATO and Reserve Forces - a Czech View," The Officer, 2013, available at: http://www.mzv.cz/nato.brussels/en/news_articles_speeches/index_2.html.

${ }^{11}$ Shima Keene, The Effective Use of Reserve Personnel in the U.S. Military: Lessons From the United Kingdom Reserve Model (Carlisle, PA: Strategic Studies Institute and U.S. Army War College Press, 2015), available at www.strategicstudiesinstitute.army.mil/pubs/ display.cfm?pubID $=1245$.

12 Sergio Catignani, "Israeli Defence Forces Organizational Changes in an Era of Budgetary Cutbacks," RUSI Journal 149, no. 5 (2004), 72-76.

${ }^{13}$ Erna Danielsson and Berit Carlstedt, "The Swedish Reserve Officer: Filling Vacancies or Using Competences," Armed Forces \& Society, 2011, 37(2), 284-300

${ }^{14}$ Republic of Serbia, Ministry of Defence, Questionnaire on Active Reserve, 2014, in Serbian, available at www.mod.gov.rs/upitnik/.

15 James Griffith, Shelley Perry, John Rauch, James Greenless, Sandra Baker, Carin Rauch, Lori Toskin, Mike Rhoads and Charles Wolters, Survey of United States Army Reserve (USAR) Troop Program Unit (TPU) Soldiers, Technical Report AD-A237 406 (Rockville, MD: Westat Inc., 1991).

${ }^{16}$ Republic of Serbia, Ministry of Defence, Public Call for the Active Reserve, available at http://www.mod.gov.rs/sadrzaj.php?id_sadrzaja=7891.

${ }^{17}$ Danielsson and Carlstedt, "The Swedish Reserve Officer."

18 Tibor Szvircsev, "Challenges in the Recruitment of Professional Soldiers in Europe," Strategic Impact no. 3 (2008): 76-86.

${ }^{19}$ Steven Blockmans and Giovanni Faleg, "Crises in the Neighbourhood Should Push CSDP Forward," European Neighbourhood Watch 113 (March 2015), available at www.ceps.eu/ sites/default/files/CEPS/NWatch113_final.pdf.

${ }^{20}$ Valeri Ratchev, Todor Tagarev, Vesselin Petkov, Antonia Todorova, and Pinar Elman, “Case Study on South-Eastern Europe," Deliverable 8.2, EvoCS Consortium, 31 July 2015, available at http://dx.doi.org/10.11610/evocs.d82. 
${ }^{21}$ Ratchev et al., "Case Study on South-Eastern Europe."

22 Tibor Szvircsev, "Challenges in the Recruitment of Professional Soldiers in Europe."

${ }^{23}$ Ratchev et al., "Case Study on South-Eastern Europe."

${ }^{24}$ Tibor Szvircsev, "Challenges in the Recruitment of Professional Soldiers in Europe."

${ }^{25}$ Milos Jovanovic and Joachim Burbiel, "The Evolving Concept of Security: A Critical Evaluation Across Four Dimensions," Future Security 2014 Conference, Berlin, September 16-18, 2014, 502-507.

${ }^{26}$ Jovanovic and Burbiel, "The Evolving Concept of Security: A Critical Evaluation across Four Dimensions."

27 Jovanovic and Burbiel, "The Evolving Concept of Security: A Critical Evaluation across Four Dimensions."

${ }^{28}$ Danielsson and Carlstedt, "The Swedish Reserve Officer."

Nebojsa NIKOLIC is a research associate at the Strategic Research Institute of the Serbian Ministry of Defence. Prior to academic work at the Institute and at the Military Academy, he performed various duties in military units. His research interests include decision making theory, strategic management, multi-criteria ranking problems, simulation, logistics and other disciplines relevant to defence and military organisations. 